\title{
Accounting for the Growth of Government
}

\author{
by \\ Gary S. Becker and Casey B. Mulligan \\ University of Chicago \\ November 1999 \\ preliminary, for discussion only
}

\begin{abstract}
Why has government grown in so many countries during the 20th century? We present a simple model of political competition and show how different sources of the growth of government have different effects on the amount and structure of taxes, spending, and regulatory programs undertaken by the government. Those sources include: demographic shifts, more efficient taxes, more efficient spending, a shift in the "political power" from those taxed to those subsidized, shifts in political power among taxed groups, and shifts in political power among subsidized groups. We also show how the effects of each source varies according to the model of public decision-making.

Based on a variety of empirical indicators of regulation, we suggest that regulation has grown over the last 100 years, but less rapidly than tax revenues. Regulation grew more slowly during the 1980's and, according to some measures, declined. We suggest that the long term regulatory and budgetary trends are consistent with growth in the political power of those subsidized - especially the elderly. The 1980's decline in regulation together with its growth in taxes is not consistent with any one of the theories of government growth.
\end{abstract}

"We appreciate the comments of Dan Kahan, Ed Laumann, Bill Landes, Sam Peltzman, John Wallis, and seminar participants at Clemson University, and the research assistance of John Allread and Rob McMillan. 


\section{Introduction}

Why has government grown in so many countries during the 20th century? Many explanations have been proposed, explanations ranging from an increased demand for government services to changes in the distribution of skill. Our study helps estimate the importance of each theory by partitioning the set of possible explanations according to their implications for the quantity, composition, and incidence of taxes, spending, and regulation. The partition is the following categories:

(i) increases in the efficiency of taxes, spending, and/or regulation

(ii) decreases (increases) in the political power of taxpayers (those subsidized)

(iii) changes in the political power of particular taxpaying or subsidized groups

(iv) demographic shifts

We begin with an interest group model to derive the implications of (i)-(iv) for the quantity, composition, and incidence of taxes, spending, and regulation. The "social redistribution" and "merit good" models often have similar implications for the effects of (i)-(iv) on taxes, spending, and regulation; we discuss those cases when the three models differ.

We present some evidence on the growth of American federal, state and municipal spending together with some crude aggregate measures of federal regulation over the period 1890-1990, and the subperiods 1890-1930, 1930-1980, 1980-1990. Improvements in the measurement of the quantity, composition, and incidence of regulation are desperately needed, but the empirical analysis serves three purposes. First, it illustrates how one might account for the growth of government using our framework. Second, we compare a remarkable variety of aggregate measures of federal regulation and show how each of them apparently grows less rapidly than taxes and spending. Third, we offer some tentative conclusions regarding the sources of the growth of government. Growth in the "political power" of the elderly appears to be an important source of the growth of government because both spending and regulation benefitting the elderly has grown relatively rapidly over the entire period - and probably over each of the subperiods. More efficient means of tax collection may have facilitated the growth of government between 1890 and 
1980, since nonelderly government programs have also grown (albeit less slowly) and spending apparently more rapidly than regulation. The 1980's witnessed a reduction in regulation, an increase in government spending (although at a slower rate than for previous periods), and a constant share of government spending on the elderly despite their substantial growth in numbers, which we cannot explain with any single one of the theories we consider.

We show how, in principle, a study of the quantity, composition, and incidence of taxes, spending, and regulation can not only distinguish among potential causes for the growth of government, but also among the various models of public decision-making by which those causes affect public policy. This proves to be difficult in practice because each of the models considered - interest group competition, social redistribution, and merit goods - have in common the majority of their implications for public policy responses to various stimuli. If, as our evidence suggests, increased tax efficiency and power of the elderly are the main stimuli, then all three public decision models predict the same changes in the composition of spending and regulation. The three models do differ according to their predictions for the amount and incidence of nonelderly regulation, but not enough is known about regulation for us to favor one model over the others.

\section{The basic interest group model}

Consider a simple model of competition for political power between two interest groups, A and B (this is an extension of the political competition model developed by Becker 1983 and Becker and Mulligan 1998). At the equilibrium, group $A$ is made worse off in order to make group B better off. Let $I$ denote an "index of interference", which measures how much the government is doing to interfere with $\mathrm{A}$ in order to benefit B. The index might denote amounts of taxes collected or regulations imposed on A. Group A spends resources, $A$, on lobbying legislators, influencing voters, etc. to persuade them to vote to keep taxes or regulations relatively low. Conversely, B spends resources, $B$, also trying to influence legislators and the electorate to vote to raise the transfers to them or beneficial (from $B$ 's point of view) regulation of group A.

We bypass an explicit discussion of the process involved in reaching government decisions on spending, taxes, and regulation. Instead, we assume a reduced form "influence function" that is the end result of what may be a very complicated process of electoral voting, legislative decisions, and executive branch initiatives. In this reduced form, government spending and regulation directly depend on the amounts $A_{I}$ and $B_{I}$ spent on gaining political influence: 


$$
I=F_{I}\left(\theta A_{I}, \lambda B_{I}\right) \text {, where } F_{a}<0, F_{b}>0, F_{a a}>0 \text {, and } F_{b b}<0 \text {. }
$$

where $\theta$ and $\lambda$ are parameters indexing the "political power" of $A$ and $B$, respectively. The derivatives mean that increased political pressure by the taxed group A lowers government spending and regulation, while increased pressure by the subsidized group B raises government spending and regulation of the A's, and both effects are subject to diminishing returns.

Each group is assumed to spend the amount on influencing the political outcome that maximizes its net income, given political spending by the other group. In the noncooperative equilibrium, each group is maximizing, given the equilibrium level of spending by the other group. Therefore, group A minimizes the sum of its political spending and the cost to members of its group of the taxes or regulations assessed against it. The cost of government activity per group member is $C\left(I / \alpha, \delta_{I}\right)$, where $\alpha$ is group A's share of the population and $\delta_{I}$ is the parameter indexing the dead weight cost (dwc) of each dollar of taxes (or each unit of regulation) used to achieve the index of interference $I / \alpha$ per member of group A. So A minimizes

$$
A_{I} / \alpha+C\left(I / \alpha, \delta_{I}\right)
$$

Since per member costs are likely to be nonlinear in interference per member, aggregate costs for the group are likely to depend on the group's size $\alpha$ as well as aggregate pressure $A$ and the aggregate index of interference $I$.

Similarly, B maximizes the difference between the value to members of B of the subsidies it receives and the amount it spends on political activity. The value of the subsidy is $S\left(I / \beta, \sigma_{I}\right)$, where $\beta$ is B's share of the population $(\alpha+\beta=1)$ and $\sigma_{I}$ is a parameter indexing the dwc to the B's of each dollar of taxes (or each unit of regulation) used to achieve the index of interference $I / \beta$ per member of group B. So B maximizes

$$
S\left(I / \beta, \sigma_{I}\right)-B_{I} / \beta
$$

We interpret aggregate pressures $A_{I}$ and $B_{I}$, aggregate costs $\alpha C$, and aggregate benefits $\beta S$ as fractions of potential aggregate GDP. Although we recognize that actual GDP responds to the amount of government interference, henceforth we hold potential GDP fixed and suppress any reference to it.

\section{II.A. Regulations vs Taxes and Subsidies}


Although textbook analyses often suggest that cash transfers dominate regulation, this is no longer true once the deadweight costs of raising and spending the cash are taken into account: a taxpayer changes his behavior to avoid the taxes and a subsidized person changes his behavior to increase his subsidy. The reduction in labor supply occurring in order to reduce incomes and thereby decrease tax liabilities or increased subsidies is one well-known example of such change behavior. Hence, we assume that income is redistributed by two means in a political equilibrium: taxes and regulations. We let $T$ and $R$ denote these two indices of interference, which are determined according to the political pressures $A_{T}, A_{R}, B_{T}, B_{R}$ applied by the two groups:

$$
\begin{aligned}
& T=F_{T}\left(\theta A_{T}, \lambda B_{T}\right) \\
& R=F_{R}\left(\theta A_{R}, \lambda B_{R}\right)
\end{aligned}
$$

We assume for simplicity that each index of interference is measured in the same units (say, dollars) as the pressures $A_{T}, A_{R}, B_{T}, B_{R}$. This is more natural when taxes are the means of interference, but might also apply to regulation if the index $R$ were measured in the right way. We also decompose the costs and benefits of interference $I$ into a "transfer" $I$ and a "deadweight loss" so that the functions $C$ and $S$ are:

$$
\begin{gathered}
C\left(I / \alpha, \delta_{I}\right)=(I / \alpha)+\delta_{I} \Delta_{I}(I / \alpha) \\
S\left(I / \beta, \sigma_{I}\right)=(I / \beta)-\sigma_{I} \Sigma_{I}(I / \beta) \\
\Delta_{I}^{\prime \prime}, \Sigma_{I}^{\prime \prime} \geq 0 \quad, \quad I=T, R
\end{gathered}
$$

Notice that, when $\Delta$ and $\Sigma$ are positive, $I$ costs group A more than $I$ and benefits group B less than $I$.

The social deadweight cost of government is $\Delta_{T}+\Delta_{R}+\Sigma_{T}+\Sigma_{R}$ plus the resources groups devote to influencing policy, $A_{T}+A_{R}+B_{T}+B_{R}$. We do not assume that $\Delta_{T}+\Delta_{R}+\Sigma_{T}+\Sigma_{R}$ is positive for all government activities or even that marginal social deadweight cost be positive for all government activities. Taxes, subsidies, and mandates "correcting market failures" or "providing public goods" are government activities which may have negative average and marginal social deadweight cost. We only assume $\Delta_{T}{ }^{\prime \prime}$, $\Sigma_{T}{ }^{\prime \prime}, \Delta_{R}{ }^{\prime \prime}, \Sigma_{R}{ }^{\prime \prime} \geq 0$ - that the marginal government tax, transfer, or regulation has the largest marginal deadweight cost.

Our notation (2) and interpretation suggest that the government has a budget constraint for interference that balances - namely that, other than the dead-weight costs, every unit of interference enjoyed by group B is a unit of interference suffered by group A. Our suggestion is quite natural when "interference" refers to taxes and spending, but less natural when interference refers to regulation. However, another legitimate interpretation of the equations (2) is as definitions of the deadweight costs as a function of the total costs $C$ and surpluses $S$ - that the "dwc" suffered by each A (each B) from interference $I / \alpha$ per A $\left(I / \beta\right.$ per B) is defined to be the difference between $C\left(I / \alpha, \delta_{I}\right)$ and $I / \alpha$ (the difference 
between $I / \beta$ and $\left.S\left(I / \alpha, \delta_{I}\right)\right)$. What is crucial for our results that this difference be a convex function of $I$.

Each group knows the "political process" $F_{T}$ and $F_{R}$ and applies pressures $A_{T}$ and $A_{R}\left(\right.$ or $B_{T}$ and $B_{R}$ ) to maximize their net surplus per member taking as given the pressure applied by the other group and the number of group members.

A minimizes: $C_{T}\left(T / \alpha, \delta_{T}\right)+C_{R}\left(R / \alpha, \delta_{R}\right)+\left(A_{T}+A_{R}\right) / \alpha$

B maximizes: $S_{T}\left(T, \sigma_{T}\right)+S_{R}\left(R, \sigma_{R}\right)-\left(B_{T}+B_{R}\right) / \beta$

A few relevant assumptions have been made above. First, given the parameters $\delta_{T}, \delta_{R}, \sigma_{T}, \sigma_{R}$, the costs of taxes are independent of the costs of regulation. It is unclear whether, in fact, the marginal deadweight cost of taxes is increasing in the amount of regulation (as in the case of payroll taxes and minimum wage regulations) or vice-versa, although an interesting analysis of such interactions is possible. ${ }^{1}$ Second, since $A_{T}, A_{R}, B_{T}, B_{R}$ are separate choice variables, groups are assumed to be able to perfectly target their political pressure towards either taxes or regulation. ${ }^{2}$ In other words, political pressure is "specific" to an index of interference. We explore the consequences of this assumption by imposing the constraints $A_{T}=A_{R}$ and $B_{T}$ $=B_{R}$ on the problems describing the groups' political behavior, which means that pressure is "general" rather than "specific".

The first order conditions describing the optimal pressures are:

$$
\begin{aligned}
-\theta\left(\partial F_{T} / \partial A\right)\left(1+\delta_{T} \Delta_{T}^{\prime}\right) & =1,-\theta\left(\partial F_{R} / \partial A\right)\left(1+\delta_{R} \Delta_{R}{ }^{\prime}\right)=1 \\
\lambda\left(\partial F_{T} / \partial B\right)\left(1-\sigma_{T} \Sigma_{T}{ }^{\prime}\right) & =1, \lambda\left(\partial F_{R} / \partial B\right)\left(1-\sigma_{R} \Sigma_{R}{ }^{\prime}\right)=1
\end{aligned}
$$

The left-hand-side of each first order condition is the marginal benefit (in "dollars") of pressure, which depends on four factors: (1) the group's political power index $(\theta$ or $\lambda),(2)$ the magnitude of the first derivative of the influence function $F_{T}$ or $F_{R}$, (3) the deadweight cost parameter $\left(\delta_{T}, \delta_{R}, \sigma_{T}\right.$, or $\left.\sigma_{R}\right)$, and (4) interference per group member.

The first two factors each increase the marginal benefit. Since A's are trying to decrease interference and B's increase it, an increase in the relevant deadweight cost parameter increases the marginal benefit of pressure for the A's and decreases it for the B's. Of particular interest is the fourth factor, interference per group member. The deadweight cost functions $\left(\Delta_{T}, \Delta_{R}, \Sigma_{T}\right.$, or $\left.\Sigma_{R}\right)$ are nonconcave,

${ }^{1}$ Summers et al (1993), for example, suggest that some labor market regulations decrease the marginal deadweight cost of labor income taxes.

${ }^{2}$ Another way of stating this assumption is that $F_{T}$ is independent of $A_{R}$ and $B_{R}$ while $F_{R}$ is independent of $A_{T}$ and $B_{T}$. 
so more interference tends to increase marginal deadweight costs. This is an important source of the dependence of political outcomes on groups size (and one emphasized by Becker 1983). Furthermore, aside from nonzero cross-derivatives of the influence functions, the fourth factor is the way in which one group's pressure affects the other groups marginal benefit of pressure. More pressure by one group tends to increase the marginal benefit of pressure by the other group unless the cross-derivative of the relevant influence function is sufficiently far from zero.

Since we place no restrictions on the magnitude of the first derivatives of the influence functions $F_{T}$ and $F_{R}$ or even the sign of the marginal deadweight costs, the first order conditions (3) show that our definition of "political equilibrium" does not presume there is either too little or too much government interference. Negative equilibrium average and marginal deadweight costs are perfectly consistent with our model.

Before deriving the effects of the various parameters on equilibrium taxes and spending, we mention some examples of changes in those parameters. Aging and increased retirement in an economy where taxes are on labor income and subsidies are mainly for the elderly is an example in the growth of the fraction of people subsidized (ie, a decrease in $\alpha$ and an increase in $\beta$ ). The invasion of an enemy army can be a circumstance of a decrease in average and marginal deadweight cost (equivalently, and increase in average and marginal benefits) of spending and regulation - namely those that help defend against the enemy. Technological and structural economic changes - such as increased urbanization and monetization of the economy or decreased monitoring costs - can allow taxes, subsidies, and regulations to be administered more efficiently. ${ }^{3}$

\section{II.B. Equilibrium Mix of Regulations and Cash Transfers}

Our model is convenient for analyzing the effect of various parameter changes on the quantity, composition, and incidence of regulations and cash transfers. A few of the parameter changes have been derived in the literature and used to explain the growth of government - as in Kau and Rubin (1981), Turner (1984), Wilson (1990), and Becker and Mulligan (1998) - but our purpose here is to contrast the implications of various theories from the literature. As we show below, the theories have substantially different empirical implications.

The first order conditions with respect to $A_{T}$ and $B_{T}$ alone determine the reaction functions and the

${ }^{3}$ Becker and Mulligan (1998) emphasize that $\delta$ parameterizes "tax efficiency" in the sense that (for $\Delta^{\prime}>0$ ) a lower $\delta$ means lower average and marginal deadweight costs of taxes for any given amount of taxes to be collected. 
Nash equilibrium $A_{T}, B_{T}$, and $T$. These equations are studied more carefully by Becker and Mulligan (1998). The first order conditions with respect to $A_{R}$ and $B_{R}$ alone determine the reaction functions and the Nash equilibrium $A_{R}, B_{R}$, and $R$.

Proposition 1 With perfectly "specific" pressure, an exogenous change in the efficiency of taxes $\delta_{T}$ or the efficiency of spending $\sigma_{T}$ affects the Nash equilibrium $A_{T}, B_{T}$, and the size of the budget $T$, but not $A_{R}, B_{R}$, or the quantity of regulation $R$. An exogenous change in the efficiency of regulation $\left(\delta_{R}\right.$ or $\left.\sigma_{R}\right)$ affects the Nash equilibrium $A_{R}, B_{R}$, and the amount of regulation $R$, but not $A_{T}, B_{T}$, or the size of the government budget $T$.

Proposition 1 is a strong result and obviously depends on our assumption that dwcs are important and that groups can expend resources to change taxes without changing regulation and vice versa. But the qualitative result - that $\delta_{\mathrm{T}}$ and $\sigma_{\mathrm{T}}$ have a greater effect on taxes than on regulation - is quite general and, as we demonstrate below, allows us to distinguish changes in tax or spending efficiency from changes in the political power of those taxed or subsidized.

Henceforth, we restrict our attention to particular Nash equilibria: those that are "stable" and "strategically separable". The stability condition is familiar from game theory and restricts how B's reaction function might cross $\mathrm{A}$ 's in the $[A, B]$ plane. Unfamiliar is "strategic separability", by which we mean an exogenous increase in A's pressure or an exogenous decrease in B's pressure decreases equilibrium interference. ${ }^{4}$ Our "strategic separability" restricts the magnitude of the cross-derivative $F_{a b}$, but is weaker than additive separability (ie, is weaker than $F_{a b}=0$ ).

The stability and strategic separability of the equilibrium gives us a Corollary to Proposition 1 ,

Corollary An increase in efficiency of taxes or spending increases $T$ relative to $R$. An increase in the efficiency of regulation increases $R$ relative to $T$.

\section{II.C. Causes of the Growth of Government Budgets}

A number of reasons for the growth of government budget can be analyzed, which we do in Propositions 2 - 4:

${ }^{4}\left(F_{a b}\right)^{2}-F_{a a} F_{b b}>0$ at an equilibrium is sufficient for the equilibrium to be "stable." $-F_{b} F_{a a} /\left(-F_{a}\right)$ $<F_{a b}<F_{a} F_{b b} / F_{b}$ at the equilibria is necessary and sufficient for the equilibria to be "strategically separable." If the influence functions are either additively separable or homogeneous of degree zero, then any Nash equilibrium is stable and strategically separable. 
Proposition 2 A decrease in the political power of the taxed group $(\theta)$ or an increase in the power of the subsidized group $(\lambda)$ increases aggregate taxes.

Proposition 3 An increase in the efficiency of taxes or spending (which is a decrease in $\delta_{T}$ or $\sigma_{T}$ when $\Delta_{T}{ }^{\prime}$ or $\Sigma_{T}^{\prime}$ are positive) increases taxes and spending. If political pressure is somewhat "general," an increase in the efficiency of regulation (which is a decrease in $\delta_{R}$ or $\sigma_{R}$ when $\Delta_{R}{ }^{\prime}$ or $\Sigma_{R}{ }^{\prime}$ are positive) increases taxes and spending.

Proposition 4 An increase in the efficiency of regulation increases regulation. If political pressure is somewhat "general," an increase in the the efficiency of taxes or spending increases regulation.

Propositions 3 and 4 point out that, when pressure is somewhat "general", the amount of taxation depends on the efficiency of regulation and the amount of regulation depends on the efficiency of taxation. Even with completely specific pressure, these dependencies would arise if the marginal deadweight costs of taxation (regulation) were decreasing in the amount of regulation (taxation).

We begin to summarize these results of the interest group (IG) model in Table 1 and the Appendix Table. The Tables also summarize results for two other models of government activity: the social redistribution (SR) model and the merit goods (MG) model. The SR and MG models are discussed in section III. In order to simplify the exposition, we look ahead to our empirical findings and report in Table 1 theoretical results for only three sources of government growth (more efficient taxes, more efficient regulation, and growing political influence of one subsidized group) and the empirical measures that might be used to distinguish them (the amount of regulation, the composition of taxes and spending taxes per regulation, and the relative incidence of taxes and regulation). Our framework can also distinguish among five other sources of government, which we compare in the Appendix Table. 
Table 1: Accounting for the Growth of Government

(both General and Specific Pressure)

\begin{tabular}{|c|c|c|c|c|c|}
\hline \multirow[b]{5}{*}{ Source of growing spending $\&$ taxes } & \multirow{5}{*}{$\begin{array}{c}\text { Model of } \\
\text { Public } \\
\text { Decisions }^{\dagger \dagger}\end{array}$} & \multicolumn{3}{|c|}{ changes in } & \multirow[b]{2}{*}{ correlation } \\
\hline & & \multicolumn{3}{|c|}{ composition } & \\
\hline & & amount of & of & taxes & between \\
\hline & & regulation & spending \& & per & regulation \& \\
\hline & & & regulation & regul. & tax incidence \\
\hline \multirow[t]{3}{*}{ more efficient taxes or spending } & IG & + & 0 & + & + \\
\hline & $\mathrm{SR}$ & - & 0 & + & + \\
\hline & MG & + & 0 & 0 & - \\
\hline \multirow[t]{3}{*}{ more efficient regulation ${ }^{\ddagger}$} & $\mathrm{IG}$ & + & 0 & - & + \\
\hline & SR & - & 0 & + & + \\
\hline & MG & + & 0 & 0 & - \\
\hline power of one subsidized group & IG, SR & $+^{*}$ & yes & 0 & + \\
\hline \multirow{2}{*}{\multicolumn{6}{|c|}{$\begin{array}{l}\text { Notes: }{ }^{*} \text { result requires somewhat stronger assumptions than stability and strategic separability }\left(F_{a b}=0\right. \\
\text { sufficient })\end{array}$}} \\
\hline & & & & & \\
\hline \multicolumn{6}{|c|}{${ }^{\dagger}$ Models of Public Decisions: $\mathrm{IG}=$ interest group, $\mathrm{SR}=$ social redistribution, $\mathrm{MG}=$ merit goods } \\
\hline
\end{tabular}

According to our Table 1, data on the amounts and composition of taxes, spending, and regulation are not enough to say whether growing government derives from increases in the efficiency of taxes or of spending. We can, however, distinguish these causes from a mere increase in the (relative) power of those subsidized because the former predict an increase in taxes per regulation. With measures of the efficiency of taxes and spending, we can begin to distinguish increased tax efficiency from increased spending efficiency, and show elsewhere how to do so (see our 1998 analysis of wartime and "flypaper" effects).

It is also easy to show that the effects of tax and spending efficiency on tax collections increases with the relative political power of those subsidized. From Young's Theorem, it then follows that more relative political power for those subsidizes leads to a greater increase in government when efficient means of distribution are available. Hence, increased efficiency of redistribution (the "supply" of government) and increased political power of those demanding redistribution (the "demand" for government) are complementary explanations for the growth of government. Some in the literature, such as Kau and Rubin (1981) have suggested that the supply and demand models are alternative explanations for government growth. 
How do demographic shifts affect aggregate interference, interference per taxpayer, and interference per person subsidized? Holding fixed aggregate interference $I$, a movement of some people from the subsidized group to the taxed group increases $I / \beta$ which decreases the marginal benefit of $\$ 1$ of pressure by group B. But the same movement of people decreases $I / \alpha$ and, because the marginal deadweight cost of taxes is lower for the larger taxpaying group, decreases the marginal benefit of $\$ 1$ of pressure by group A. With both groups reducing their pressure, we cannot sign the effect on aggregate interference. The reduced pressure by group A is likely to dominate when deadweight losses are more convex on the taxpayer side or when the taxpaying group is relatively small.

It is unambiguous, however, that $I / \alpha$ must fall and $I / \beta$ increase. There is a large literature suggesting that group size is an important determinant of taxes per taxpayer and subsidies per person subsidized, with smaller subsidized groups enjoying more subsidies (or beneficial regulation) per member and larger tax paying groups enjoying fewer taxes or (less costly regulation) per member. ${ }^{5}$

\section{II.D. Predictions for the Composition of Spending, Taxes, and Regulation}

In order to analyze the composition of spending and taxes, we introduce an additional taxed group for a total of three groups: $A_{1}, A_{2}$, and $B$ with population shares $\alpha_{\mathrm{b}} \alpha_{2} \beta\left(\alpha_{1}+\alpha_{2}+\beta=1\right)$. Let $A_{T_{1}}\left(A_{R}\right)$ denote the political pressure applied by taxpaying group $i$ against the subsidized group in order to reduce taxes (regulation) and let $T_{i}\left(R_{i}\right)$ denote the amount of taxes (regulation) levied against group $i$. Let $B_{T}\left(B_{R}\right)$ denote the political pressure applied by the subsidized group $\mathrm{i}$ in order to increase taxes (regulation).

$$
\begin{gathered}
T_{i}=F_{T}\left(\theta_{\mathrm{i}} A_{T i}, \lambda B_{T}\right), R_{i}=F_{R}\left(\theta_{\mathrm{i}} A_{R i}, \lambda B_{R}\right), \\
A_{i} \text { minimizes: } C_{T i}\left(T_{i} / \alpha_{i}, \delta_{T i}\right)+C_{R i}\left(R_{i} / \alpha_{i}, \delta_{R i}\right)+\left(A_{T i}+A_{r i}\right) / \alpha_{i}, i=1,2 \\
B \text { maximizes: } S_{T}\left(\left(T_{1}+T_{2}\right) / \beta, \sigma_{T}\right)+S_{R}\left(\left(R_{1}+R_{2}\right) / \beta, \sigma_{R}\right)-\left(B_{T}+B_{R}\right) / \beta
\end{gathered}
$$

We interpret the parameters as in the two group case, and point out that a similar set of assumptions are made about the nature of politics and interference: costs of taxes are independent of the costs of regulation and political pressure is specific to either taxes or regulation. We also assume that the subsidized group cannot target its pressure against a particular taxpaying group.

We continue to restrict our attention to stable and strategically separable Nash equilibria. ${ }^{6}$

${ }^{5}$ See Wittman (1989, p. 77) for a discussion. Demsetz (1982), Friedman and Friedman (1980), Becker (1983) and others derive this result.

${ }^{6}$ With three groups, more complicated restrictions on the pressure and deadweight cost functions are required to guarantee that any Nash equilibrium is stable and strategically separable. 
Proposition 5 states the familiar separability result which, of course, would not hold if political pressure were general:

Proposition 5 With perfectly "specific" pressure, an exogenous change in the efficiency of taxes $\left(\delta_{T 1}\right.$ or $\delta_{\mathrm{T} 2}$ ) or the efficiency of spending $\left(\sigma_{T}\right)$ affects the Nash equilibrium $A_{T 1}, A_{T 2}, B_{T}$, and the size of the budget $T=T_{1}+T_{2}$, but not $A_{R 1}, A_{R 2}, B_{R}$, or the quantity of regulation $R=R_{1}+R_{2}$. An exogenous change in the efficiency of regulation $\left(\delta_{R 1}, \delta_{R 2}\right.$ or $\left.\sigma_{R}\right)$ affects the Nash equilibrium $A_{R 1}, A_{R 2} B_{R}$ and the amount of regulation $R$, but not $A_{T 1}, A_{T 2}, B_{T}$, or the size of the government budget $T$.

Although complete separability of the politics of taxes and regulation would not occur if political pressure were general to some degree, we still expect $\delta_{T 1}, \delta_{T 2}$ and $\sigma_{T}$ to have greater effects on taxes than on regulation and $\delta_{R 1}, \delta_{R 2}$ and $\sigma_{R}$ to have greater effects on regulation than on taxes.

Some other familiar results can be obtained from the three group model and are reported in Propositions 6 - 7:

Proposition 6 An increase in the power of the subsidized group $(\lambda)$ increases taxes and regulations levied on both taxpaying groups.

Proposition 7 A decrease in the political power of taxed group $i\left(\theta_{i}\right)$ increases taxes and regulation paid by $i$. The change in $\theta_{i}$ must either increase aggregate taxes or decrease taxes paid by the other taxed group (and either increase aggregate regulation or decrease regulation paid by the other taxed group). If the influence functions are additively separable, then aggregate taxes and regulation increase and taxes and regulation paid by the other taxed group decrease.

Stability and strategic separability are not sufficient to guarantee that less power by some taxpayers (and more taxes paid by them) decrease taxes and regulation levied against other taxpayers. This can be seen in the special case that $\Sigma "=0$ and $F_{a b}$ is negative (but not so negative so as to violate strategic separability): the decrease in $A_{i}$ increases the marginal product of pressure for the subsidized group. The subsidized group raises its pressure. Since strategic separability has been assumed, B's increase cannot be enough to increase $T_{i}$. However, to the extent that B's pressure cannot be targeted towards $A$, more

Additively separable influence functions and nonconcave deadweight cost functions are sufficient but not necessary. 
pressure is applied against the other taxed group which can increase taxes paid by that group (and thus aggregate taxes).

Additive separability of the influence functions $\left(F_{a b}=0\right)$ and strict convexity of B's deadweight costs $\left(\Sigma^{\prime \prime}>0\right)$ is sufficient to guarantee that less power by some taxpayers increase aggregate taxes and regulation and decrease taxes and regulation levied against other taxpayers. Our Table 1 assumes that aggregate taxes and regulation increase and, more weakly, that the composition of taxes and regulation changes.

"Political power" is relative in our model, so it is important to notice that we model a decrease in the power of taxed group $i\left(\theta_{i}\right)$ as a decrease relative to the other taxed group and relative to those subsidized. In other words, the relative power of those subsidized and the other taxed group is unchanged. A decrease in the power of taxed group $i$ that does not change the power of $i$ relative to those subsidized will still change the composition of taxes as indicated in Proposition 7, but need not lead to an increase in total taxes and spending.

Propositions 3-4 considered "exogenous" changes in the efficiency of taxes, subsidies, and regulation. Our results in this regard are most interesting when there are "exogenous" differences over time or across governments in technology, industrial composition, or government knowledge of public finance that permit exogenous differences in tax efficiency. But a government's system of taxes, subsidies, and regulations may become more efficient because those harmed by the more efficient taxes and regulations lose political power, or because those benefiting from more efficient subsidies and regulations gain political power. These possibilities can be worked out in the version of our model with two taxed (or two subsidized groups) by shifting the index of political power for the group with the lower $\delta_{T}$ or $\delta_{R}$ (or $\sigma_{T}$ or $\sigma_{R}$ ) and applying Proposition 7. Even if $\lambda$ were decreased so as to remain unchanged relative to an average of $\theta_{1}$ and $\theta_{2}$, we expect government to grow because resistance by the efficiently taxed group is relatively more important while that group is least willing to resist because it suffers relatively few deadweight costs for a given amount of revenue to be extracted from it. But this endogenous increase in tax efficiency is different from the exogenous increase considered in the first row of Table 1 because: (a) the composition of taxes changes, (b) the composition of spending changes, and (c) there is no change in taxes per regulation.

Proposition 8 An increase in the efficiency of spending (which is a decrease in $\sigma_{T}$ when $\Sigma_{T}$ ' is positive) increases taxes levied on both taxed groups. An increase in the efficiency of regulation for group B (which is a decrease in $\sigma_{R}$ when $\Sigma_{R}$ is positive) increases regulation levied on both taxed groups. If political 
pressure is somewhat "general," an increase in the efficiency of regulation for group B increases taxes levied on both taxed groups and an increase in the efficiency of spending increases regulations levied on both taxed groups.

Proposition 9 An increase in the efficiency of taxes for one taxed group (which is a decrease in $\delta_{T i}$ when $\Delta_{T i}{ }^{\prime}$ is positive) increases taxes levied on that group. An increase in the efficiency of regulation for one taxed group (which is a decrease in $\delta_{R i}$ when $\Delta_{R i}{ }^{\prime}$ is positive) increases regulation levied on that group. If political pressure is somewhat "general," an increase in the efficiency of regulation for one taxed group increases taxes levied on that group and an increase in the efficiency of taxes for one taxed group increases regulations levied on that group.

Proposition 7 suggests that stronger assumptions are required to sign the effects of one groups tax efficiency on the other taxed group and on aggregate taxes. Proposition 10 makes the required assumption.

Proposition 10 Let $F_{a b}=0$. An increase in the efficiency of taxes for one taxed group decreases taxes levied on the other group and increases aggregate taxes. An increase in the efficiency of regulation for one taxed group decreases regulation levied on the other group and increases aggregate regulation. If political pressure is somewhat "general," an increase in the efficiency of regulation for one taxed group decreases taxes levied on the other group and increases aggregate taxes while an increase in the efficiency of taxes for one taxed group decreases regulation levied on the other group and increases aggregate regulation.

By introducing an additional taxed group into the two group model, we have derived results for the composition of taxes. An analogous set of results could be derived for the composition of spending by introducing an additional subsidized group. We do not present the details of the analysis here, but enter the analogous results in the Appendix Table.

\section{Interest Group Approach Compared with Other Models of Public Decisions}

We model public decisions as an outcome of a competition among interest groups, but there are a number of other models of public decisions in the literature. Three of those - the efficiency maximization, social redistribution, and merit good models - have in common the majority (but not all) of their implications for public policy responses to various stimuli. Hence, in principle, accounting for the growth of government requires identifying a growth stimulus and a model of the effect of that stimulus on 
public policy. In practice, the different implications of the public decision models are too subtle for us to test with our data.

\section{III.A. Efficiency Maximization}

Many have suggested that government policy can be described as maximizing efficiency (taking as given that each person paying taxes and being subsidized will act in his individual interest). The literature includes Wittman's (1995) claim that democratic institutions are efficient and Barro's (1979) argument that U.S. federal government debt policy efficiently allocated tax burdens over time. Efficiency can be defined in our model as the set of transfers $\left(T_{1}, T_{2}, R_{1}, R_{2}\right)$ minimizing the sum of deadweight costs across those paying taxes and receiving subsidies (although this ignores the costs associated with attempts to influence policy in our model):

$$
\begin{gathered}
\alpha_{1} \delta_{\mathrm{T} 1} \Delta_{T 1}\left(T_{1} / \alpha_{1}\right)+\alpha_{2} \delta_{T 2} \Delta_{T 2}\left(T_{2} / \alpha_{2}\right)+\alpha_{1} \delta_{R 1} \Delta_{R 1}\left(R_{1} / \alpha_{1}\right)+\alpha_{2} \delta_{R 2} \Delta_{R 2}\left(R_{2} / \alpha_{2}\right)+ \\
\beta \sigma_{T} \Sigma_{T}\left(\left(T_{1}+T_{2}\right) / \beta\right)+\beta \sigma_{R} \Sigma_{R}\left(\left(R_{1}+R_{2}\right) / \beta\right)
\end{gathered}
$$

A necessary condition for efficiency maximization is the equation of marginal deadweight costs across various taxes described by Frank Ramsey (1927).

Although there are no influence functions $F_{T}$ and $F_{R}$ satisfying our assumptions (1) for which the equilibrium is the efficient set of transfers, there are functions that would approximate it arbitrarily closely. Thus we consider efficiency maximization as a limiting case of our analysis. ${ }^{7}$

In addition to equating marginal dwc across types of taxes and regulations, efficiency maximization has strong implications for the level of taxes and regulation. Namely, the aggregate marginal dwc of each tax and each regulation is zero:

$$
\begin{gathered}
\delta_{\mathrm{T} 1} \Delta_{T 1}{ }^{\prime}\left(T_{1} / \alpha_{1}\right)+\sigma_{T} \Sigma_{T}{ }^{\prime}\left(\left(T_{1}+T_{2}\right) / \beta\right)=0 \\
\delta_{\mathrm{T} 2} \Delta_{T 1}{ }^{\prime}\left(T_{2} / \alpha_{2}\right)+\sigma_{T} \Sigma_{T}{ }^{\prime}\left(\left(T_{1}+T_{2}\right) / \beta\right)=0 \\
\delta_{\mathrm{R} 1} \Delta_{R 1}{ }^{\prime}\left(R_{1} / \alpha_{1}\right)+\sigma_{R} \Sigma_{R}{ }^{\prime}\left(\left(R_{1}+R_{2}\right) / \beta\right)=0 \\
\delta_{\mathrm{R} 2} \Delta_{R 1}{ }^{\prime}\left(R_{2} / \alpha_{2}\right)+\sigma_{R} \Sigma_{R}{ }^{\prime}\left(\left(R_{1}+R_{2}\right) / \beta\right)=0
\end{gathered}
$$

In other words, taxes and regulations are used only because they enhance efficiency.

In that limiting case, the amount of regulation is independent of the efficiency of taxes and the amount of taxation is independent of the efficiency of taxes or spending, as in our Propositions 1 and 5. However, not all interest group pressure is general so, in the interest group model, we expect more efficient taxes to increase regulation and more efficient regulation to increase taxes. The other qualitative results

${ }^{7}$ The limiting case is $F(A, B)$ proportional to $B-A$. 
reported in Table 1 are shared by the efficiency maximization model. The efficiency maximization model has been modified in the literature in two important ways, which we refer to as the "social redistribution" and "merit good" models.

\section{III.C. Social Redistribution}

The efficiency model has been enhanced, most famously by Mirrlees (1971), by allowing for a social objective for redistribution. In our notation, this might be thought of as maximizing a monotonic "social welfare function" of each group's surplus. ${ }^{8}$ Groups do not enter symmetrically in the social welfare function, because some group's surplus is assumed to contribute more to "social welfare" than others. For example, as in the utilitarian models, the surplus of each group contributes to social welfare in proportion to its average marginal utility. Political power and other considerations can also be reflected in the form of the social welfare function. We refer to this model as the social redistribution (SR) model.

Adding a social welfare function to the efficiency model has important implications for the amount of tax, spending, and regulation. Taxes and regulations can be used beyond the point of efficiency - so that equilibrium aggregate marginal deadweight costs are positive - in order to transfer resources from groups receiving less importance in the social welfare function to groups receiving more importance.

It is straightforward to derive implications from the SR model for the effect of changes in the relative size of the taxpaying and subsidized groups, and those implications are similar to those of the IG model. Some implications differ between the SR and IG models, and we discuss those in section IV.

\section{III.D. Merit Goods}

Over some range, the aggregate marginal deadweight cost of regulation $\Delta_{R}{ }^{\prime}+\Sigma_{R}{ }^{\prime}$ may be negative. For example, some regulations may be used to discourage activities with negative external effects ("demerit goods") and encourage activities with positive external effects ("merit goods"). The merit and demerit goods can have external effects in the technical sense - as with pollution or donating blood - or it may be that some citizens prefer to see other citizens consume merit goods and avoid demerit goods. Regulations encouraging merit behavior and discouraging demerit behavior may harm some individuals, even though they enhance aggregate efficiency.

This environment is included as a special case of our interest group model, because nowhere have we ruled out the possibility that $\Delta_{R}{ }^{\prime}+\Sigma_{R}{ }^{\prime}<0$. As a special case, our Table 1 predictions for the amount,

${ }^{8}$ It has been shown (eg., Mueller 1989; Ledyard 1984) how democratic and other political institutions might deliver policies as if a social welfare function were being maximized. 
mix and incidence of taxes, spending, and regulation are the same even if most of regulatory activity is motivated by efficiency considerations (ie, $\Delta_{R}{ }^{\prime}+\Sigma_{R}{ }^{\prime}<0$ ) rather than as a means of redirecting resources to the politically powerful. In particular, the existence of such regulation does not, according to the IG model, tell us anything about the quantity or composition of taxes and spending.

As long as there are losers from the marginal regulation, political competition as we have modeled it does not guarantee that the efficient amount of regulation will occur (ie, to the point where $\Delta_{R}{ }^{\prime}+\Sigma_{R}{ }^{\prime}=$ 0 ). Indeed, there will tend to be less regulation than is efficient (ie, equilibrium $R$ is such that $\Delta_{R}{ }^{\prime}+\Sigma_{R}{ }^{\prime}$ $<0)$ unless those who benefit most from efficient regulation also happen to be the politically powerful. The negative marginal deadweight costs mean that, starting from zero regulation, those who gain from regulation have more incentive to fight for regulation than those who lose have incentive to fight back political competition can move regulation in the direction of efficiency. ${ }^{9}$ However, the gainers run into diminishing returns to political pressure and hence have a lesser incentive to fight for additional regulation. Only if the gainers also enjoy more than average political power can it be expected that they will continue to pressure for regulation up to or beyond the point where aggregate efficiency is maximized.

Hence, even ignoring the inefficient "rent-seeking" nature of political action, our interest group model leaves some gains from trade in the case when $\Delta_{R}{ }^{\prime}+\Sigma_{R}{ }^{\prime}<0$. This leaves open the possibility that, excluded from our model, are political institutions which can arrange for those who lose from regulations (say, the B's) to be granted a cash transfer from those who gain (say, the A's). Some (eg., Harberger 1984, Sala-i-Martin 1996, Mulligan and Philipson 1999, and many others) have argued that the bulk of government spending can be understood as payment by those who want changes in behavior to those changing their behavior (which Mulligan and Philipson call "purchasing merit goods"). The authors argue that schooling, health expenditures, and an early retirement are important examples of merit goods.

One institution that might exploit these gains from trade is a protocol for bargaining between the two interest groups (A's and B's in our model). A social redistribution model would also predict these gains from trade to be exploited and, assuming that the social motives for redistribution discussed in subsection III.D are relatively unimportant (ie, each group's surplus enters the social welfare function symmetrically), those who benefit from regulation would pay taxes to subsidize those harmed. This mechanism for public decisions analyzed by Mulligan and Philipson (1999), which we refer to as the merit good (MG) model. It is really a special case of the social redistribution model, but a different case than we consider above for which redistribution of resources to the poor and/or the politically powerful are the primary motives for policy. We refer to this latter case as the social redistribution (SR) model.

${ }^{9}$ This point is made by Becker (1983). 
Sala-i-Martin (1996) has argued that one of the largest government programs, Social Security, is an exchange of cash transfers for merit goods. The merit good is elderly leisure (because, he argues, more leisure by the old enhances productivity for the young), the cash transfer is a Social Security check, and regulation requires that recipients of the cash transfer exit the labor force. Olsen and York (1984), Mulligan and Philipson (1999), have argued that housing assistance, public medical insurance, public retirement savings programs, and other subsidy programs are also an exchange of cash transfers for merit goods.

\section{Explanations from the Literature as Special Cases of Our Model}

The analysis summarized in Table 1 and the Appendix Table allows a reader to categorize various explanations for the growth of government according to their implications for the level and composition of taxes, spending, and regulation. We illustrate this with a number of examples from the literature.

\section{IV.A. Better Technologies for Tax Collection}

Building on the insights of Brennan and Buchanan (1980), Buchanan and Lee (1982), Wilson (1990), and others, Kau and Rubin (1981) and Becker and Mulligan (1998) blame some of the growth of government over time on the emergence of better means of tax collection. Theirs is an increase in the efficiency of taxes for all taxpayers (a reduction in the parameters $\delta_{T 1}$ and $\delta_{T 2}$ when $\Delta_{T}{ }^{\prime}>0$ ) and results in more spending, more taxes, more regulation, more taxes per regulation, and no change in the composition of taxes, spending, and regulation.

As long as there are multiple policy instruments for achieving the socially optimal distribution of income, the SR model equates aggregate marginal deadweight costs across each instrument - as in the efficiency maximizing model. For example, if the poor, or the elderly, or some other preferred group can be assisted with both cash transfers and regulations, the aggregate marginal deadweight cost of transfers will be equated to the aggregate marginal deadweight cost of regulation. This means that an exogenous enhancement of the efficiency of taxes (regulation) decreases the use of regulation (taxes). This is an important difference from the predictions of the IG model, so we enter separate rows for the SR model in Table 1 and in the top part of the Appendix Table.

Taxes, spending, regulation are simultaneously determined in the MG model. Taxes are levied in order to compensate losers from regulation, and regulation is politically acceptable because the losers can be compensated with subsidies. Hence, an increase in the efficiency of taxes increases the scope for compensating the losers from regulation, and thereby increases regulation - as with the IG model. 
Regulation also increases in the IG model, but the incidence of the regulatory and tax changes are very different. The same group gains from additional taxes and regulation (namely, the B's) in the IG model while those who gain from the additional regulation in the MG model are those who lose from additional taxes and spending. The IG and MG models differ in similar ways according to the public policy response to an increase in the efficiency of regulation.

\section{IV.B. Changes in Military Spending}

Military spending is, of course, affected by domestic political forces. But, with the intention of explaining government policies during wars like World War II or the policies of a threatened state like Israel or Egypt, consider an increase in military spending motivated by "efficiency" considerations. This fits into our analysis as an increase in the efficiency of spending and, because the efficiency of nonmilitary spending is roughly unchanged, an increase in efficiency for only a subset of those subsidized (ie, a reduction in $\sigma_{\mathrm{T} 1}$ holding $\sigma_{\mathrm{T} 2}$ and other parameters constant). As shown in the Appendix Table, we predict an increase in spending, a reduction in nonmilitary spending, and an increase in taxes.

The need to fight a war may also be associated with an increase in the efficiency of regulation, ${ }^{10}$ but we presume that relatively more wartime "needs" are for Treasury revenue rather than increased mandates. Thus we cannot predict whether regulation increases or decreases, but any increase should be less than the increase in Treasury revenue. ${ }^{11}$

\section{IV.C. Changing Political Influence}

Some argue that government has grown because particular subsidized groups have gained political influence. Examples from the literature include Peltzman's (1980) theory of the homogeneity of subsidy groups, Lott and Kenny's (1999) analysis of female suffrage and Mulligan and Sala-i-Martin's (1999) study of the growing political influence of the elderly. We model this as an increase in the political power index $\lambda$ for a subset of those subsidized (or in Peltzman's case, perhaps an increase in $\lambda$ for all those subsidized).

\footnotetext{
${ }^{10}$ For example Warner and Asch (1996) and others have suggested that conscription is efficiency enhancing.

${ }^{11}$ In order to sign the effect of war on regulation, we need to make additional assumptions about the effect of war on the struggle between A's and B's. If, holding pressure constant, the effect of war is to increase total taxes and spending without reducing nondefense spending, then the increased resistance by taxpayers will result in a net decrease in regulation. If, holding pressure constant, the effect of war is to reduce nondefense spending without increasing taxes, then the increased pressure by those subsidized will result in more regulation.
} 
As reported in Table 1, we expect an increase in total spending and regulation and an increase in spending and regulation for the group gaining influence, a decline in spending and regulation benefitting others, and no change in the relative amount of spending and regulation.

As our analysis has shown, it is important in these applications that a subsidized group's power increases relative to taxpayers and relative to those not in the group and being subsidized. If the increase in political influence were only relative to other subsidy recipients, there may only be a reallocation of spending but not an increase in total spending and taxes. Some in the literature (eg., Browning 1975, Boadway and Wildasin (1989)) have derived an increase in elderly influence relative to taxpayers from the fact that many taxpayers expect to become elderly themselves. Mulligan and Sala-i-Martin (1999) also suggest that the elderly have become more "single-minded" or "group-conscious" relative to taxpayers.

The social redistribution approach typically offers an ethical rather than a positive interpretation of the marginal importance of each group's contribution to social welfare, but changes in the social welfare function, for whatever reason, might be used to explain the growth of government. The qualitative implications of, say, increased social importance of those subsidized are similar to those of the IG model in response to the growth of the political power of those subsidized. We therefore enter these implications of the SR and IG models in the same rows of Table 1.

\section{IV.D. "Corporatism"}

Summers et al (1993, pp. 385-86) and Olson (1982) explain that "corporatist" economies might make labor supply decisions collectively, and collective labor supply decisions reduce the marginal deadweight cost of labor income taxes. ${ }^{12}$ In other words, the marginal dwc of taxes and subsidies decrease with the amount of regulation. This means that taxpayers are less enthusiastic about resisting regulations against them, because such regulations have the benefit of reducing dwcs of taxes. And, given an additional amount of regulation, taxpayers have less reason to resist spending because the marginal dwc of taxes has fallen. We leave it to the reader to prove that the results in our interest group (IG) model obtain when the function $\Delta_{T}$ and $\Sigma_{T}$ depend on $R$ in this way, because the added interaction between taxes and regulation only reinforces the positive correlation between the two predicted by the model.

The "corporatism" theory may modify one of the implications of the social redistribution (SR) model of public decisions. It explains how an increase in the efficiency of regulation might lead to a

\footnotetext{
${ }^{12}$ Mancur Olson (1986) appropriately qualifies the argument, pointing out that free-riding among subcoalitions of a "collective" organization might be just as important as the free-riding among organizations.
} 
growth in taxes and spending. As explained above, the "social planner" reacts to more efficient regulation by increasing regulation but, rather then substituting away from cash transfers, the planner may increase them because the additional regulation has reduced their marginal dwc.

\section{IV.E. Marxist Theories}

Marxist theories of government also fit into our framework, where the interest groups might be labeled as "labor" and "capital". One rendition of that theory (Foley 1978) supposes that capitalists tend to control government and limit subsidies to which laborers are entitled, but that the degree of capitalist control changes over time. Growing government could then be explained by a reduction in the political power of capital which we would predict to be associated with a less favorable regulatory environment for capital as well as capital's bearing a greater share of the tax burden. A full analysis of the functional incidence of taxes, and how that incidence has changed over time, is beyond the scope of this paper, but the decline over time in the importance of property and corporate income tax revenues (Barro 1987) suggest that capital is not bearing an increasing share of the tax burden. We suggest in the next section that business regulation has increased over the century, although the trend for recent decades is more ambiguous.

\section{Evidence from the U.S.}

It is well known that government spending has grown over time in developed countries. We present time series measures of the quantity and composition of government spending, taxes and regulation in the U.S. The time series are compared with the predictions from Table 1 to evaluate which explanation(s) for the growth of government might be the primary explanation. Our preliminary empirical findings are summarized in Table 2.

\section{V.A. Spending over Time}

Figure 1 shows how American government spending has grown over time, especially at the federal level. Over the period 1890-1990, the fraction of GNP spent by the Federal government (including grants to state and local governments) has grown from 0.023 to 0.23 while real GNP grew by a factor of 25 . Thus federal government spending grew by a factor of 250 in real terms and by a factor of 10 relative to GNP. We measure general government spending (federal plus state and local, net of intergovernmental transfers) back to 1902 when the fraction of GNP spend by all levels of government was 0.066 (0.022 Federal plus 
0.044 state and local). General government spending reach $34 \%$ of GNP by 1990 - an increase by a factor of five since 1902. Interrupted only by WWII and the Korean War, the increase in government spending is spread pretty evenly over the period 1932-90. The Reagan and postReagan periods are not a quantitatively important interruption of this trend, although some of the spending has been shifted to state and local governments during this period. Government spending growth was slow for a longer period of time prior to 1930.

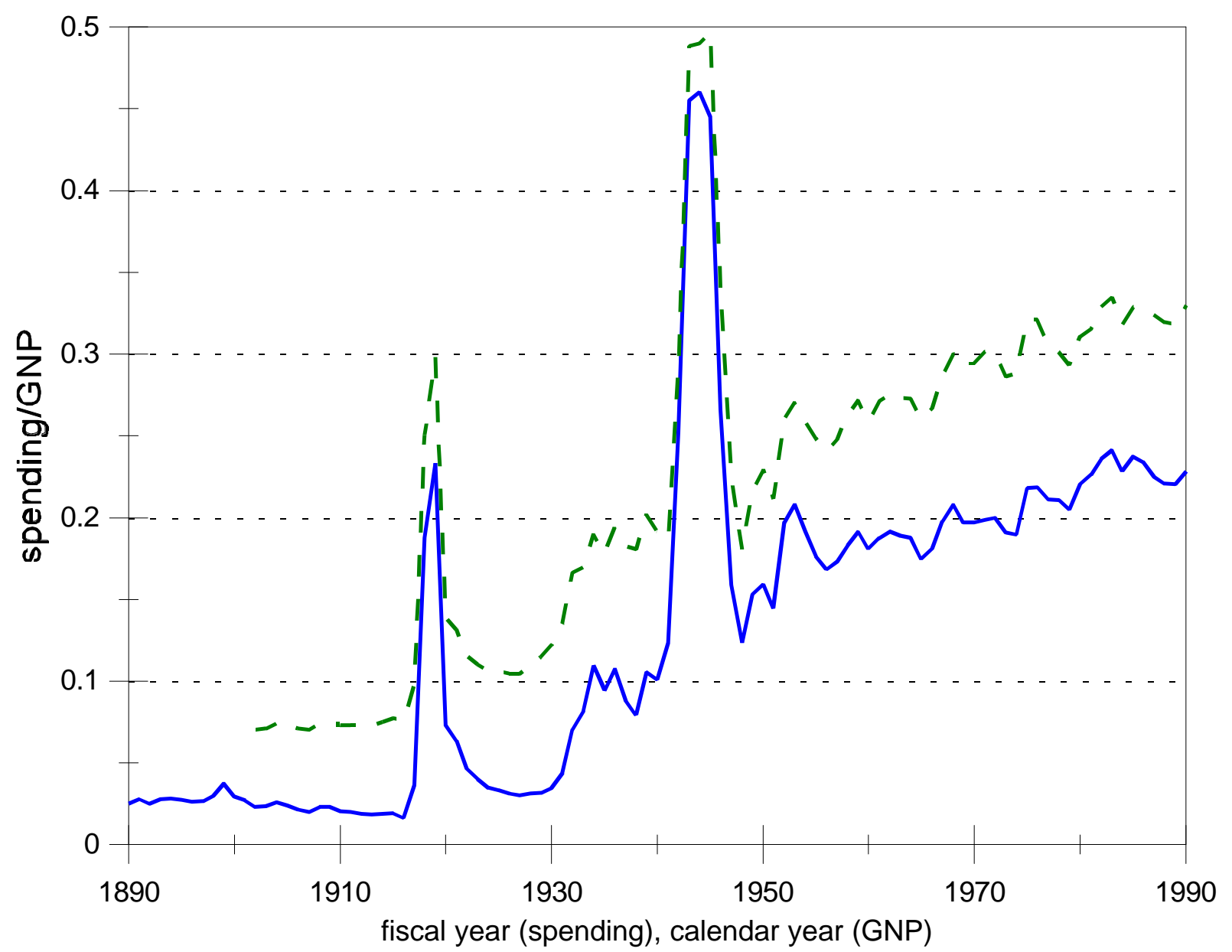

$\longrightarrow$ Federal $\quad-\quad-\quad$ Total Government

Figure 1 U.S. Spending Measures 1890-1990, normalized by real GNP 


\begin{tabular}{|c|c|c|c|c|c|}
\hline \multicolumn{6}{|c|}{$\begin{array}{l}\text { Table 2: Summary of Preliminary Empirical Measures } \\
\text { of the Amount, Composition, and Incidence of Taxes, Spending, and Regulation }\end{array}$} \\
\hline change in: & measured by: & $\begin{array}{l}1890- \\
1930\end{array}$ & $\begin{array}{l}1930- \\
1980\end{array}$ & $\begin{array}{l}1980- \\
1990\end{array}$ & $\begin{array}{l}1890- \\
1990\end{array}$ \\
\hline amount of spending & gen gov spending/GNP & $0 /+$ & + & + & + \\
\hline \multirow[t]{9}{*}{ amount of regulation } & Committee staff size & 0 & + & - & 0 \\
\hline & federal civilian employment/POP & + & + & 0 & + \\
\hline & federal civilian employment/GNP & 0 & + & - & 0 \\
\hline & Member staff size & & + & - & \\
\hline & regulatory costs/GNP & & & - & \\
\hline & regulatory costs/POP & & & 0 & \\
\hline & US code pages & & + & + & \\
\hline & gen gov civilian employment/POP & & + & 0 & \\
\hline & $\begin{array}{l}\text { gen gov civilian employment/GNP, } \\
\text { court cases, FR pages }\end{array}$ & & + & - & \\
\hline regulation/taxes & all indicators & 0 & + & - & + \\
\hline elderly spending & spending/GNP, fraction of all spending & - & + & 0 & + \\
\hline \multirow[t]{2}{*}{ elderly regulation } & business regulation & - & + & - & + \\
\hline & eldlerly labor regulation & 0 & + & + & + \\
\hline
\end{tabular}

\section{V.B. Regulation over Time: Five Indicators}

Regulation is more difficult to quantify, but Figure 2 displays eight indicators of the quantity of regulation relative to GNP over the period 1890-1990. Each of the measures is displayed in one of the frames (upper, middle, and lower). Since we are interested in the growth of regulation rather than its level, we have multiplied each measure by its own constant so that the changes over time might be seen more easily in the graph. Each frame's scale begins at zero, so a movement of a series from the first tick to the second represents a doubling of regulation, a movement from the second to the third a $50 \%$ increase, etc.

Two of those indicators - Congressional Committee Staff sizes and the number of Federal civilian employees excluding defense - are available for most of the period and do not show any substantial trend relative to GNP. ${ }^{13}$ Variations on these two series - Congressional Member Staff sizes and General Government Civilian Employment (excluding federal defense and Post Office employees) - are available

${ }^{13}$ We have only computed Congressional Committee Staff sizes for the years 1891, 1914, 1930, $1935,1947,1950,1955,1960,1965$, and 1970-90 so any high frequency variation in the associated regulation measure is from the real GNP series used in the normalization. 
for fewer years. The postwar trend relative to GNP has been downward for Federal employees and slightly upward for Congressional Committee and Member Staff sizes. General Government Civilian Employment does not trend down since the War - unlike Federal Civilian Employment - mainly because of the increased school-related employment by states and localities. Both the Congressional Committee Staff and Congressional Member Staff Size series suggest a postwar regulatory peak in the 1970's. The fastest growing of these indicators - Congressional Committee Staff sizes has grown by only a factor of 1.7 relative to GNP since 1930.

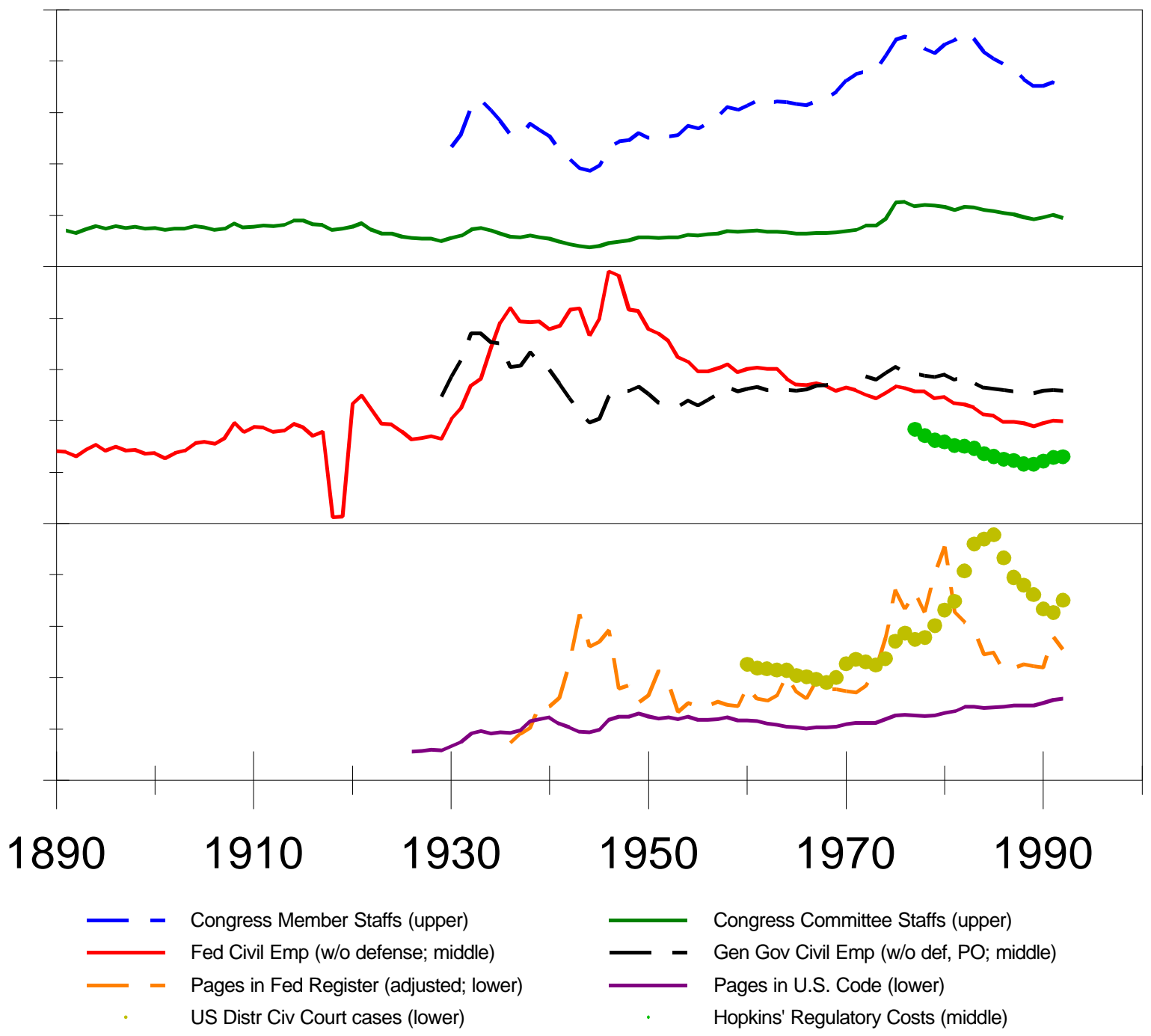

Figure 2 U.S. Regulation Measures 1890-1990, normalized by real GNP

Three other indicators of regulation are pages in the Federal Register (FR), pages in the U.S. Code of Federal Regulations, and the number of U.S. District Civil Court cases commenced. Pages in the FR 
is an interesting measure of federal regulation since, with only a few exceptions, all federal regulations are recorded there. The FR consists of laws passed by Congress, executive orders, and federal government agency reports. The inclusion of agency reports is of interest because federal agencies often interpret and elaborate on fairly vague statutes, although changes in FR rules have resulted in some increase in agency reporting that is not associated with increase regulation. ${ }^{14}$

\section{V.C. Regulation over Time: Two Refinements of FR Pages}

There are a variety of other reasons why FR pages are not a perfect quantitative measure of the amount of federal regulation. For example, extensive deregulation or reregulation might actually temporarily increase the number of pages in the FR without increasing - or even decreasing - the stock of Federal regulation. And the amount of regulation might increase substantially with a decrease in the number of pages. It can also be argued that each volume of the FR reports increments to the stock of regulation rather than the stock itself. We suggest several alternative measures that might alleviate some of these problems with FR pages. ${ }^{15}$ The first alternative is the number of pages in the U.S. Code. The U.S. Code has been issued every six years since 1926 and reports the federal statutes in effect at the time of publication. Hence, it is a more direct measure of the stock of federal regulation than is FR pages. Unlike the FR, the U.S. Code excludes executive orders and agency reports, which can be an advantage when comparing regulation before and after the period 1967-75 (see the previous footnote). Pages in the U.S. Code have increased less than pages in the FR since the 1930s and, unlike FR pages, have continued to increase since 1980. Nevertheless, pages in the U.S. Code have not increased as much as real tax revenue.

Other alternatives to FR pages are resources devoted to the enforcement of regulation government employees and the number of civil court cases. Since we believe that some categories of government employees are not typically involved with enforcing government regulations, we try to exclude

${ }^{14}$ Figure 2 includes an adjustment for the passage of the Freedom of Information, the Privacy, and the Sunshine Acts between 1967 and 1974. The Acts require additional reporting in the FR by Federal government agencies of their activities and contributed to the tripling of the page counts between 1967 and 1975 (U.S. Office of the Federal Register 1980, p. 1). We adjust all page counts after 1970 by a factor of 0.8 , an adjustment which implies that $20 \%$ of the pages would not exist in the absence of the acts and that the Acts were responsible for roughly one third of the 1967-75 page count growth.

Otherwise, our examinations suggest that the font size and legalese of the FR have been constant over time.

${ }^{15}$ As a measure of regulation, Congressional Staff Sizes also share many of the shortcomings of FR pages: large Congressional staffs might indicate an increased flow of regulation rather than a larger stock; staff sizes might be larger when lots of deregulation or reregulation occurs. 
employees such as uniformed military personnel, defense civilian employees, postal employees, and (in a series not shown in the figure) municipal school employees. Including or excluding the categories of government employees does not substantially affect the estimation of trends from the data. Court cases did not trend relative to GNP for the years 1930-70, but have increased at least 50\% relative to GNP since.

None of the regulation measures increase as rapidly as real tax revenue. But it is presumed that, without any change in interference, both real tax revenue and regulation measures would increase proportionally with real GNP. Perhaps real tax revenue should be normalized by real GNP and the regulation measures by population? We let the reader answer this question and display in Figure 3 the alternative population normalization. We see that Federal Civilian Employment (excluding defense) increases by a factor of 3 or 4 during the period 1890-1990, with most of the increase from 1890-1950. Congressional Committee Staff sizes increase by a factor of 5.5, but most of its increase is since 1950 . Factor of 3 or 4 increases relative to population are fairly typical for the regulation measures available only for the latter part of the period 1890-1990. Since federal government spending's share of GNP increased by a factor of 10 and general government's by a factor of 5 , it is difficult to refute our conclusion that taxes have grown more rapidly than regulation merely by renormalizing the regulation series. 


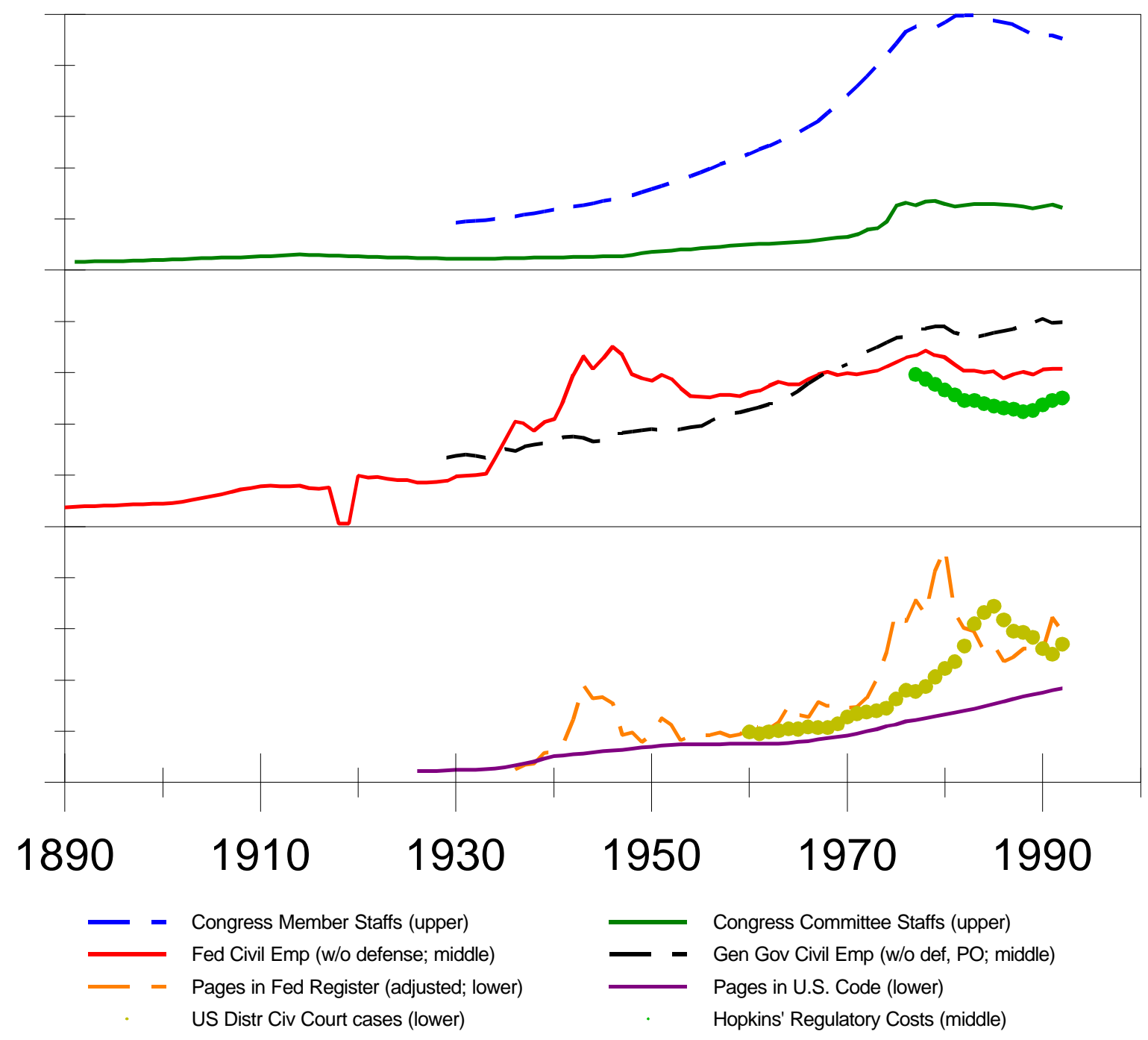

Figure 3 U.S. Regulation Measures 1890-1990, normalized by population

\section{V.D. Regulation over Time: How Well Do the Seven Indicators Track Regulatory Costs?}

It may well be that FR pages, Federal employees, and our other regulation indicators are related to the dollar cost of regulation in nonlinear way, so that the our indicators grow relatively slowly while the dollar cost grows rapidly. Hopkins' (1996) much more detailed study of Federal regulatory costs for the period 1977-94 provide a needed check on our rough indicators. Hopkins attempts to measure the total yearly dollar costs of federal regulations to those businesses, governments, and individuals "harmed" by adding together independent measures of regulation of different areas. He breaks total regulation down into three parts: (1) Environmental and Risk Reduction, (2) Price and Entry Controls, and (3) Paperwork. 
For (1), he relies largely on EPA and Dept. of Commerce Bureau of Economic Analysis data. The calculation of (3) involves straightforward multiplication of a \$26 dollar estimated wage rate, with the "annual accounting of burden hours published by the Office of Management and Budget." (Hopkins, p. 8) ${ }^{16}$ We expect this approach to yield more accurate results because it attempts to measure actual dollar costs incurred. This method also has the advantage of differentiating meaningless, unenforced, verbose regulations from those which are concise but applicable and tightly regulated.

Hopkin's and other attempts to measure the cost of regulation have the advantage of expressing cost in the same units as are taxes and spending, dollars, and hence we have some additional confidence when we find that, say, the dollar-denominated regulation series grows less rapidly than dollars collected in taxes. However, it would be even better to compare the cost of regulation with the cost of taxes, rather than with the amount of taxes. The cost of taxes may well be greater and increase more rapidly than the amount of taxes (ie, there is a deadweight cost of taxes which is a positive, increasing, and convex function of taxes).

We see in middle panels of Figure 2 and 3 that Hopkins' regulatory costs closely track the number of Federal employees (excluding defense and postal) over the period 1977-94. Their close association suggests that Federal Employees might be a good indicator of regulatory costs over longer time periods, or that Hopkins has not succeeded in uncovering a nonlinear relationship between number of employees and regulatory costs.

In summary, it is appears that regulation has increased over the century, although probably less than taxes. The increase appears slow from 1890-1930, and rapid from 1930-78. However, some of the regulation indicators have decreased from 1978 to 1990, a period when taxes continued to increase. Part of the difference between the spending and regulatory trends may be that our regulation measures are mainly federal and federal tax revenue has not really increased over this recent period.

Our Table 1 includes two stories for the growth of taxes that includes reductions in regulation greater exogenous tax efficiency in the social redistribution model and greater power of those subsidized in the merit good model. Although it is true that Reagan increased the efficiency of the personal income tax by reducing marginal tax rates and eliminating deductions, should this be viewed as an exogenous change since it is hard to identify, say, a technological source of greater tax efficiency? We suggest below that both stories are inconsistent with apparent changes in the incidence of taxes, spending, and regulation.

Hence it seems that the 1980's must be explained with a combination of theories. For example

\footnotetext{
${ }^{16}$ For a discussion of the validity of this approach, see U.S. General Accounting Office (1995). We have been unable to determine how Hopkins estimated the cost of Price and Entry Controls.
} 
Peltzman (1989) has suggested that the recent deregulation movement was motivated by decreases in the efficiency of regulation (a reduction in $\sigma_{R}$ in our notation), while government revenue increased for other reasons - perhaps an increase in the number of elderly. This is consistent with our estimates of the incidence of government spending (see below) during the 1980's: total government spending grew more slowly during the 1980's, with the elderly receiving a constant share of that spending despite their substantial increase in numbers, and probably benefitting from the 1980's regulatory changes.

\section{V.E. Defense vs. Nondefense Spending}

Figure 5 displays an indicator of the composition of U.S. government spending - it division into defense and nondefense and into elderly and nonelderly. The long term trend in the defense share of spending is slightly downward as government has grown somewhat more rapidly in nondefense areas. The medium term fluctuations are much more substantial and are relevant for our analysis. 

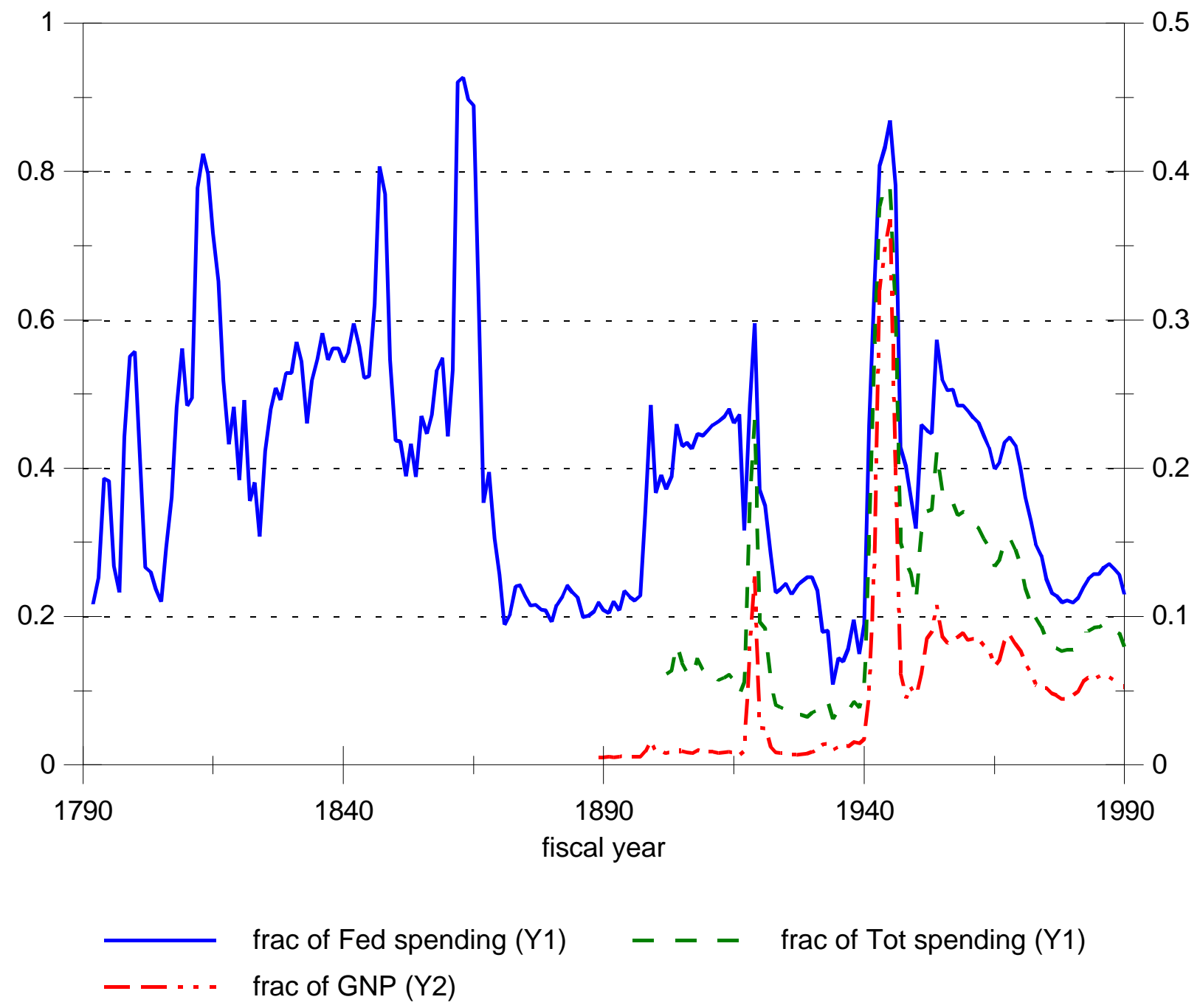

Figure 4 Relative Magnitude of Defense Spending, 1790-1990

While defense spending grew as a fraction of GNP from 1900 the 1930's, its share of spending fell. Thus an increased "need" for defense spending cannot explain the growth of government over that period because nondefense spending grew more rapidly. Increased defense spending can explain some of the growth of government from the interwar to the postwar period. However, because nondefense spending also grew during the period, an increased "need" for defense spending can only explain a fraction of the growth of government.

The end of the Cold War is another medium term change in the need for defense spending for which we predict a decline in overall spending and an increase in nondefense spending. These predictions are consistent with our data, except that the end of the Cold War has not (yet?) produced a decline in total government's spending as a fraction of GNP. 
Wartime growth of government can be well explained as an "increase in the efficiency" of defense spending or an increase in the marginal deadweight cost of nondefense spending. Consistent with Table 1, Becker and Mulligan (1998) find that nondefense spending's share of trend GDP declined substantially during World War II.

\section{V.F. Elderly vs. Nonelderly}

V.F.1 Trends in relative Spending and Taxes

According to Mulligan and Sala-i-Martin (1999), U.S. Federal government spending for the elderly grew over the period 1950-96 from $1.1 \%$ to $8.8 \%$ of GDP while their share of the population grew from $8.1 \%$ to $12.8 \%$ and all other federal spending fell from $15 \%$ to $14 \%$ of GDP. The same is true (although somewhat less dramatically) for total U.S. government spending: elderly spending grew from 1.7 to 9.4 percent of GDP while nonelderly spending stayed constant at $25 \%$ of GDP.

Becker and Murphy (1988) suggest that while government dollars spent per person over age 65 have grown over time and are greater than the government dollars (mainly education) spent per person under age 22, the rates of growth have not been different for government spending on the average elderly person and government spending on the average young person. For two reasons, their findings are not enough to conclude that the relative political power of the elderly has remained constant. First, Becker and Murphy's calculations exclude some important expenditures on the elderly (expenditures which have grown over time) -- medical, welfare, and veterans expenditures. When these items are included, Mulligan and Sala-i-Martin show that total elderly spending grows at the same rate as total youth spending over the period 1950-70, much more rapidly over the period 1970-83, and slightly more rapidly over the period 1983-96. When the elderly government spending per elderly is compared with youth spending per youth, the former grows much more rapidly over the period 1950-83 - the ratio of elderly spending per elderly to youth spending per youth tripled. The ratio falls somewhat over the period 1983-1996. Even if this were not the case that elderly spending per elderly grew more rapidly than youth spending per youth, a finding that spending per elderly has kept up with spending per young even when the former population has grown so much more rapidly may itself be evidence that the political power of the elderly has grown.

The elderly apparently do not pay a larger share of the tax burden, certainly not enough to offset their growing subsidies. Capital taxes seem to have become a relatively less important source of Federal revenue, and the elderly own relatively more capital. The Corporate Income Tax is a much less important source of Federal revenue now (roughly $10 \%$ of revenue) than it was 50 years ago (roughly $30 \%$ of revenue), while payroll taxes have grown dramatically (OMB 1997, Table 2.2). The elderly enjoy some 
special Personal Income Tax treatment such as a larger standard deduction (IRS 1997, p. 18), property tax exemptions, and special tax treatment of housing sales proceeds.

Because state and local spending is relatively more concerned with education and AFDC, results reported by Becker and Murphy (1988) and Mulligan and Sala-i-Martin (1999) show that spending on the young has also grown, although probably at a slower rate. This, together with a growing reliance on relatively efficient payroll taxes suggests that growing tax efficiency might be credited with some of the growth in government.

V.F.2 Trends in relative Regulation

There are three areas of regulation that we might categorize as favoring the elderly or taxing the elderly:

(i) regulation of business, especially environmental regulation

(ii) retirement and disability regulation

(iii) age discrimination laws

A careful analysis of the incidence of regulation (and whether a regulation even promotes its advertised objective) is well beyond the scope of this paper, but we might guess that older people own most of the capital so that regulations that tax current capital and benefit labor are harming mainly the current elderly. Perhaps this is especially true for environmental regulations which restrict the operations of current business and convey benefits decades in the future. New retirement regulation, such as the prohibition of mandatory retirement, and age discrimination laws might be seen as allowing older workers to renegotiate previous implicit contracts. Young workers, of course, would like to promise not to engage in this kind of regulation when they are older but, once they become older and the implicit contracts are given, the older worker will benefit by renegotiation.

It is unclear whether regulations of type (i) have increased or decreased over time. Over the last 100 years, it seems clear that the amount of environmental and anti-business regulation has increase more rapidly than population and probably more rapidly than GNP. This trend may have reversed with the massive deregulation around 1980. Hopkins' (1996) data shows that, while the per capita costs of environmental regulation have risen 1977-94, the per capita costs of paperwork and price and entry controls have fallen enough the total per capita cost of Federal Regulation (and perhaps also the portion of that cost falling on business) may have fallen over the period. Thus Hopkins' data suggests that the elderly may have been net gainers from regulation over the period 1977-94.

Retirement legislation and age discrimination laws (eg., the 1990 Americans with Disabilities Act, 
Regulation B of the 1975 Equal Credit Opportunity Act, and the prohibition of mandatory retirement) have undoubtably increased over time. On indicator of the increased retirement-related regulatory activity is the number of Federal District Civil Social Security court cases commenced, which increased from less than $1 \%$ to more than $5 \%$ of all Federal District Civil court cases. Our overall impression is therefore that the elderly have been net losers from regulation over the long period but net gainers over the last couple decades.

V.F.3 Interpreting the Trends

Although a lot more empirical work is needed, our preliminary evaluation of the age-incidence of taxes, spending, and regulation, suggests three conclusions:

(i) Despite their increase in numbers, elderly have enjoyed substantially more government spending per capita, even when compared to government spending on youth. This trend is most pronounced over the period 1950-83.

(ii) The elderly share of government spending is constant in the 1980's, despite their increase in numbers over this period.

(iii) Prior to 1970, it is unclear whether regulation favored the elderly. Since 1970, changes in regulation have tended to favor them.

Explanations for the postwar growth of elderly spending have been proposed in the literature. Some attribute the change to the growing political power of the elderly. Others (eg., Sala-i-Martin 1996) argue that old age programs have grown because their potential for enhancing efficiency has grown. Still others (eg., Becker and Mulligan 1998) attribute the growth of government - and the growth of old age programs in particular - to increased reliance on relatively "efficient" taxes such as flat-rate payroll taxes.

As shown in Table 1, each of these explanations have different predictions for the amount and composition of regulation affecting the elderly. A growth in political power should be accompanied by increasingly favorable regulation, which is consistent with our evaluation of spending and regulation for the period since 1970. However, we see little evidence of regulation favoring the elderly prior to 1970. Second, growing elderly power alone would predict important reductions in nonelderly spending while in fact these reductions, if any, were modest. Third, the source of the growing elderly political power remains unexplained.

The payroll tax was introduced in the 1930's and withholding payroll at the source began in 1943. It might therefore be argued that redistribution to the elderly became more efficient during that period, 
which would explain why tax and spending programs favoring them grew relative to other tax and spending programs and relative to regulations favoring them. The SR model even predicts regulation to increasingly hurt the elderly.

Whether or not the increased tax efficiency is "exogenous" or the result of reductions in the political power of those more burdened with the efficient taxes can be tested by looking at changes in the level and composition of regulation. A complete analysis of the incidence of payroll taxes is beyond the scope of our paper, but it is possible that employers are among those harmed (at least in the short run) by payroll taxes. If it were the case that employers were losing their political power, then we should also see growing regulation harming employers. With the Americans with Disabilities Act, the Medical Leave Act, and increasing minimum wages, it does appear that employers are losing political power. However, these labor market interventions are quite recent. It might be argued that employers enjoyed increased political power over most of the period since 1950 - minimum wages fell and unions lost their influence. Hence, it appears that least part of the growth of spending on the elderly must be attributed to their growing political power, or to "exogenous" increases in tax efficiency, rather than a reduction in the political power of those harmed by payroll taxes.

We have also noted that growing political power of those subsidized and increasing efficient taxes are complementary explanations for the growth of government. The growing political power would have had little effect on government spending unless that spending could be expanded without sizable dwcs. And the increasing efficiency of taxes would not have increased subsidies for the elderly unless they were powerful enough to obtain them.

\section{Summary and Conclusions}

Beginning with an interest group model of government interference, we partition potential explanations for the growth of government into four categories: increases in the efficiency of taxes, spending, and/or regulation, decreases (increases) in the political power of taxpayers (those subsidized), changes in the political power of particular taxpaying or subsidized groups, and demographic shifts. We then derive implications of each type of explanation for the quantity and composition of taxes, spending, and regulation.

Our own interpretation of the interest group model of public decisions and initial investigation of American measures of government interference suggest that the two biggest contributors to the growth of U.S. government are the increased efficiency of means of tax collection and increased political power of the elderly. The reasons for our conclusions can be seen by comparing Tables 1 and 2. According to Table 
2 , spending and regulation have grown, and spending more rapidly than regulation - as if in response to more efficient means of taxation. However, Table 2 also suggests the composition of spending and regulation has tilted toward the elderly, which is consistent with a growth in their political power.

We suggest that the public policy responses to efficient of means of tax collection, increased political power of the elderly, and other stimuli would be different in other models of public decisions, such as the social redistribution and merit good models. Various models of public decisions do differ according to their predictions about the effect of efficient tax collection and increased elderly power on the amount and incidence of nonelderly regulation, but the available data seems too crude to conduct such a test.

We believe our partition can usefully guide future empirical and theoretical work on the long standing question "Why has government grown?" Some of the many remaining questions are: How might the quantity and composition of regulation be measured? What are some of the important taxed and subsidized groups and why has their influence changed over time? How might the efficiency of taxes and subsidies be measured? Why has the political influence of the elderly grown over time?

\section{Appendix I - Data Sources}

Congressional Staff Sizes. 1980-1990: Ornstein et al (1998). 1891-1979: Bibby et al (1980, citing Fox et al 1977). For all years, Congressional Member staff size is computed as the sum of House and Senate Member Staff sizes; Congressional Committee staff size is computed as the sum of House and Senate Committee Staff sizes.

Federal Register Pages. Total number of pages in the each year's Federal Register, multiplied by 0.8 after 1970 (an adjustment for the passage of the Freedom of Information, the Privacy, and the Sunshine Acts between 1967 and 1974). With the exceptions of 1936, 1937, and the first 1100 pages of 1938, all of the years appear to be of the same font, point, and format: three column pages, 78 lines to the column, approx. 7 words to the line.

GNP. 1965-1990: Citibase GNP series, calendar year average of quarterly values. 1890-1964: U.S. Bureau of the Census (1975), Series D-802 (calendar year values, multiplied by 1.034 to merge with Citibase series).

Government Employment, Federal (w/o military and Post Office). 1971-1990: U.S. Office of Management and Budget (1996), Tables 17.2 and 17.3 (Legislative and Judicial Branches plus Civilian Agencies). 1890-1970: U.S. Bureau of the Census (1975), Series Y-315, Y-316, Y-317 (Executive Branch, excluding 
military and Post Office, plus Legislative and Judicial Branches).

Government Employment, All Levels (w/o military and Post Office). 1971-1990: Federal series plus State and Local from U.S. Office of Management and Budget (1996), Table 17.3. 1890-1970: Federal series plus U.S. Bureau of the Census (1975), Series Y-332 (State and Local government employment).

Government Expenditure, Federal. 1934-1990: U.S. Office of Management and Budget (1996), Table 1.1 (fiscal year outlays). 1890-1933: U.S. Bureau of the Census (1975), Series Y-457 (fiscal year outlays). Government Expenditure, All Levels. 1947-1990: U.S. Office of Management and Budget (1996), Table 15.2 (fiscal year expenditures). 1890-1946: U.S. Bureau of the Census (1975), Series Y-522 (fiscal year expenditures, multiplied by 1.131 to merge with OMB series). Series Y-522 available only in the years $1902,1913,1922,1927$, and in the even years 1932-46; missing years linearly interpolated as a fraction of GNP.

Government Expenditure, Federal Defense. 1965-1990: U.S. Office of Management and Budget (1996), Table 4.1 (fiscal year "military-defense" outlays), minus $\$ 1.624$ (the average difference between the OMB and Census Bureau series for the overlapping years 1963-70). 1890-1964: U.S. Bureau of the Census (1975), Series Y-458 and Y-459 (fiscal year outlays for Departments of Army and Navy).

Government Expenditure, Elderly. Mulligan and Sala-i-Martin (1999).

Regulatory Costs. Hopkins (1996).

U.S. Code Pages. Total number of pages in each volume of the Code of Federal Regulations (which has been issued every six years since 1926). Words per page appear to be the same in each volume.

U.S. District Civil Court Cases, all categories. U.S. District Civil Court cases commenced in the year ending June 30 (1960-1990) or September 30 (1991-), according to Judicial Conference of the United States (a.k.a. Judicial Business of the United States) Tables C-2 and C-3.

U.S. District Civil Court Cases, Social Security. U.S. District Civil Court Social Security cases commenced in the year ending June 30 (1960-1990) or September 30 (1991-), according to Judicial Conference of the United States (a.k.a. Judicial Business of the United States) Tables C-2 and C-3.

\section{Appendix II - Account for other Sources of Government Growth}




\begin{tabular}{|c|c|c|c|c|c|c|c|c|}
\hline \multirow[b]{3}{*}{ Source of growing spending $\&$ taxes } & \multirow[b]{3}{*}{ Model } & \multirow{2}{*}{\multicolumn{6}{|c|}{$\begin{array}{r}\text { changes in } \\
\end{array}$}} & \multirow{3}{*}{$\begin{array}{l}\text { correlation } \\
\text { between } \\
\text { regulation \& } \\
\text { tax incidence }\end{array}$} \\
\hline & & & & & & & & \\
\hline & & $\begin{array}{l}\text { amount of } \\
\text { regulation }\end{array}$ & $\begin{array}{r}\text { comp } \\
\text { spending }\end{array}$ & $\begin{array}{l}\text { osition } \\
\text { regul. }\end{array}$ & $\begin{array}{l}\text { of: } \\
\text { taxes }\end{array}$ & $\begin{array}{r}\text { taxes } \\
\text { member }\end{array}$ & $\begin{array}{l}\text { per: } \\
\text { regul. }\end{array}$ & \\
\hline \multirow[t]{3}{*}{ efficient taxes or spending - exogenous ${ }^{* * *}$} & $\mathrm{IG}$ & + & 0 & 0 & 0 & + & + & + \\
\hline & SR & - & 0 & 0 & 0 & + & + & + \\
\hline & MG & + & 0 & 0 & 0 & + & 0 & - \\
\hline \multirow[t]{3}{*}{ eff. regulation - exogenous ${ }^{\ddagger, * * *}$} & IG & + & 0 & 0 & 0 & + & - & + \\
\hline & SR & - & 0 & 0 & 0 & + & + & + \\
\hline & MG & + & 0 & 0 & 0 & + & 0 & - \\
\hline \multirow[t]{2}{*}{ less power by all taxpayers } & IG, SR & + & 0 & 0 & + & + & 0 & + \\
\hline & MG & - & 0 & 0 & + & + & + & - \\
\hline relatively more taxpayers ${ }^{\dagger}$ & $\begin{array}{c}\mathrm{IG}, \mathrm{SR} \\
\mathrm{MG}\end{array}$ & $?$ & 0 & 0 & 0 & - & 0 &,,++- \\
\hline relatively more subsidized & $\begin{array}{c}\mathrm{IG}, \mathrm{SR} \\
\mathrm{MG}\end{array}$ & $?$ & 0 & 0 & 0 & - & 0 &,,++- \\
\hline eff. taxes (some taxpayers) - exogenous & IG, SR & $+^{*},-$ & 0 & yes $^{* *}$ & yes & $+^{*}$ & + & + \\
\hline power of one taxed group & IG, SR & $+^{*}$ & 0 & yes & yes & $t^{*}$ & 0 & + \\
\hline eff. spending (some) - exogenous & $\mathrm{IG}, \mathrm{SR}$ & $+^{*},-$ & yes & yes & 0 & $++^{*}$ & + & + \\
\hline power of one subsidized group & IG, SR & $+^{*}$ & yes & yes & 0 & $+^{*}$ & 0 & + \\
\hline \multicolumn{9}{|c|}{$\begin{array}{l}\text { Notes (see also notes for Table } 1 \text { ): } \\
\text { whether aggregate spending and taxes are increased by relatively more taxpayers or more of those subsidized depends on the } \\
\text { parameters of the model } \\
\text { *** composition changes are different from those for the IG model } \\
* * * * \text { "exogenous" changes in efficiency are reductions in } \delta_{T}, \sigma_{T}, \delta_{R} \text {, or } \sigma_{R} \text {. }\end{array}$} \\
\hline
\end{tabular}




\section{References}

Barro, Robert J. "On the Determination of the Public Debt." Journal of Political Economy. 87(5), October 1979: 940-71.

Becker, Gary S. "A Theory of Competition among Pressure Groups for Political Influence." Quarterly Journal of Economics. 98(3), August 1983: 371-400.

Becker, Gary S. and Casey B. Mulligan. "Deadweight Costs and the Size of Government." NBER Working paper \#6789, October 1998.

Becker, Gary S. and Kevin M. Murphy. "The Family and the State." Journal of Law and Economics. 31(1), April 1988: 1-18.

Bibby, J.F., T.E. Mann, and N.J. Ornstein. Vital Statistics on Congress, 1980. Wash. DC: American Enterprise Institute for Public Policy Research, 1980. p. 69-71.

Brennan, H. Geoffrey and James M. Buchanan. The Power to Tax: Analytical Foundations of a Fiscal Constitution. Cambridge, MA: Cambridge University Press, 1980.

Boadway, Robin W. and David E. Wildasin. "A Median Voter Model of Social Security." International Economic Review. 30(2), May 1989: 307-28.

Browning, Edgar K. "Why the Social Insurance Budget Is Too Large in a Democracy." Economic Inquiry. 13(3), Sept. 1975: 373-88.

Buchanan, James M. and Roger Congleton. "Proportional and Progressive Income Taxation with Utility-Maximizing Governments" Public Choice. 34(2), 1979: 217-30.

Buchanan, James M. and Dwight R. Lee. "Politics, Time, and the Laffer Curve." Journal of Political Economy. 90(4), August 1982: 816-19.

Demsetz, Harold. Economic, Legal, and Political Dimensions of Competition. Amsterdam: NorthHolland, 1982.

Foley, D. K. "State Expenditures from a Marxist Perspective." Journal Public Economics. 9,1978: 22138.

Fox, H.W. Jr. and S.W. Hammond. Congressional Staffs: The Invisible Forcein American Lawmaking. New York: The Free Press, 1977. p.171.

Friedman, Milton and Rose D. Friedman. Free to Choose. New York: Harcourt Brace Jovanovich, 1980.

Harberger, Arnold C. "Basic Needs versus Distributional Weights in Social Cost-Benefit Analysis." Economic Development and Cultural Change. 32(3), April 1984: 455-74.

Hopkins, Thomas D. Regulatory Costs in Profile. CSAB Policy Study Number 132, August 1996.

Judicial Conference of the United States. Annual Report of the Director. Washington D.C.: Statistics 
Division of the Administrative Office of the United States Courts, various issues.

Kau, James B. and Paul H. Rubin. “The Size of Government.” Public Choice. 37(2), 1981: 261-74.

Ledyard, John O. "The Pure Theory of Large Two-Candidate Elections.” Public Choice. 44(1), 1984: $7-41$.

Lott, John, Jr. and Larry Kenny. "Did Women's Suffrage Change the Size and Scope of Government?" Forthcoming, Journal of Political Economy, 1999.

Mirrlees, James A. “An Exploration in the Theory of Optimal Income Taxation.” Review of Economic Studies. 38, 1971: 175-208.

Mueller, Dennis C. Public Choice II. Cambridge: Cambridge University Press, 1989: 124-34.

Mulligan, Casey B. and Tomas J. Philipson. "Policy Design and Incidence in a Merit Good Economy." Working paper, University of Chicago, June 1999.

Mulligan, Casey B. and Xavier Sala-i-Martin. “Gerontocracy, Retirement, and Social Security.” NBER Working Paper \#7117, May 1999.

Olsen, Edgar O. and Kathy A. York. "The Effect of Different Measures of Benefit on Estimates of the Distributive Consequences of Government Programs." in Marilyn Moon, ed. Economics Transfers in the United States. Studies in Income and Wealth, vol. 49. Chicago and London: University of Chicago Press 1984: 177-95.

Olson, Mancur. The Rise and the Decline of Nations. New Haven, CT: Yale University Press, 1982.

Olson, Mancur. “An Appreciation of the Tests and Criticisms." Scandinavian Political Studies. 9(1), March 1986: 65-80.

Ornstein, Norman J., Thomas E. Mann, and Michael J. Malbin. Vital Statistics on Congress 1997-1998. Washington, DC: American Enterprise Institute, 1998.

Peltzman, Sam. "The Growth of Government." Journal of Law and Economics. 23(2), October 1980: 209-87.

Peltzman, Sam. "George Stigler's Contribution to the Economic Analysis of Regulation." Journal of Political Economy. 101(5), October 1993: 818-32.

Ramsey, Frank. “A Contribution to the Theory of Taxation.” Economic Journal. 37, March 1927: 47-61.

Sala-i-Martin, Xavier X. "A Positive Theory of Social Security." Journal of Economic Growth. (1)2, June 1996: 277-304.

Summers, Lawrence H., Jonathan Gruber, and Rodrigo Vergara. "Taxation and the Structure of Labor Markets: The Case of Corporatism." Quarterly Journal of Economics. 108(2), May 1993: 385-411. 
Turner, John A. "Population Age Structure and the Size of Social Security." Southern Economic Journal. 50(4), April 1984: 1131-46.

United States Department of Labor, Women's Bureau. British Policies and Methods in Employing Women in Wartime. Women's Bureau Bulletin no. 200. Washington, DC: U.S. Government Printing Office, May 1944.

United States Department of Labor, Women's Bureau. State Labor Laws for Women with Wartime Modifications. Women's Bureau Bulletin no. 202. Washington, DC: U.S. Government Printing Office, 1945.

U.S. General Accounting Office. "Regulatory Reform: Information on Costs, Cost-Effectiveness, and Mandated Deadlines for Regulations," GAO/PEMD-95-18BR, March 1995.

United States, Department of Commerce, Bureau of the Census. Historical Statistics of the United States, Colonial Times to 1970. Bicentennial edition. Washington: U.S. Dept. of Commerce, Bureau of the Census, 1975.

United States Office of the Federal Register. Code of Federal Regulations. Washington, DC: Office of the Federal Register, various issues.

United States Office of the Federal Register. Federal Register. Washington, DC: Office of the Federal Register, various issues.

United States, Office of the Federal Register. The Federal Register: What It Is and How to Use It. Washington, DC: Office of the Federal Register, 1980.

United States Office of Management and Budget. Historical Tables, Budget of the United States Government, Fiscal Year 1996. Washington, DC: Government Printing Office, 1996.

United States Office of Management and Budget. Historical Tables, Budget of the United States Government, Fiscal Year 1997. Washington, DC: Government Printing Office, 1997.

Vawter, Roderick L. Industrial Mobilization: the Relevant History. Fort Lesley J. McNair, Washington, D.C.: National Defense University Press, 1983.

Warner, John T. and Beth J. Asch. “The Economic Theory of a Military Draft Reconsidered.” Defence and Peace Economics. 7(4), 1996: 297-312.

Wilson, John Douglas. "Are Efficiency Improvements in Government Transfer Policies Self Defeating in Political Equilibrium?" Economics and Politics. 2(3), November 1990: 241-58.

Wittman, Donald A. "Pressure Group Size and the Politics of Income Redistribution." Social Choice and Welfare. 6, 1989: 275-86.

Wittman, Donald A. The Myth of Democratic Failure: Why Political Institutions are Efficient. Chicago: 
University of Chicago Press, 1995. 